\title{
COMPETIÇÕES ESCOLARES: REFLEXÃO E AÇÃO EM PEDAGOGIA DO ESPORTE PARA FAZER A DIFERENÇA NA ESCOLA
}

\author{
Riller Silva Reverdito \\ Professor na Faculdade Adventista de Educação Física (UNASP-FAEF) e coordenador \\ da Área de Educação Física Escolar no Instituto Adventista São Paulo (IASP).
}

\author{
Alcides José Scaglia \\ Professor na Faculdade Adventista de Educação Física (UNASP-FAEF) e coordenador da Universidade \\ do Futebol Campus Pelé.
}

Sidney Aparecido Dias da Silva

Professor da Área de Educação Física Escolar e Especialista em Pedagogia do Esporte Escolar.

Thales Marcel Ribeiro Gomes

Professor da Área de Educação Física Escolar do Centro Educacional Terras do Engenho (LICEU).

Claudinei de Lima Pesuto

Professor da Área de Educação Física Escolar e Especialista em Pedagogia do Esporte Escolar.

Walter Baccarelli

Professor da Área de Educação Física Escolar e Especialista em Pedagogia do Esporte Escolar.

\begin{abstract}
Resumo
O tema competição sempre alimentou grandes discussões, ocasionalmente polarizadas entre os que eram favoráveis e aqueles não-favoráveis. Na perspectiva de superar essas discussões, nos propomos a fazer uma reflexão da competição enquanto elemento fundamental do esporte e apresentar uma proposta para a ação educativa a partir de suas virtudes. A proposta que defendemos, para as competições escolares, está impregnada com a responsabilidade da educabilidade do sujeito, sistematizada por princípios pedagógicos e metodológicos. Preconizamos uma ação educativa para a participação democrática de todos, diminuindo a ênfase sobre o produto, para acentuar a preocupação de um processo para o sujeito que aprende na e por meio da competição.
\end{abstract}

Palavras-chave: competição - jogos escolares - Pedagogia do Esporte.

\section{Introdução}

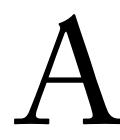

competição, principalmente no âmbito escolar, por muito tempo esteve polarizada, sendo alimentada à base de contradições $\mathrm{e}$, conseqüentemente, repelindo qualquer possibilidade de diálogo. Os pólos que alimentaram as discussões sobre competições, em diferentes abordagens, viveram, ou vivem reféns da apresentação de seus aspectos positivos de um lado e dos negativos do outro.

Dentre os principais fatores que contribuíram para as contradições dessas discussões, temos sua negação pela Educação Física, quando analisamos o número de obras que discutem a competição no espaço escolar. Idêntico modo acontece com a Pedagogia do Esporte que, mesmo reconhecendo o significativo avanço promovido pelas principais abordagens atuais, ainda são poucos os autores e obras que se dedicam efetivamente ao estudo da teoria e prática da competição escolar.

Reverdito e Scaglia (2006), no estudo das principais abordagens em Pedagogia do Esporte no Brasil, comprometidas com a ruptura ideológica e paradigmática do modelo tecnicista, destacam que elas não apresentam ou não aprofundam discussões referentes às competições. Foram encontradas propostas metodológicas para o ensino e aprendizagem dos esportes, exemplos de aulas e de jogos educativos, porém nenhum tipo de organização de competições ou ainda princípios gerais que possam nortear uma competição pedagógica, sem negá-la.

A competição é elemento fundamental do esporte, que dá sentido a sua existência, e 
é nela que a manifestação do esporte se realiza em sua plenitude. Portanto, qualquer ação orientada para o ensino e aprendizagem do esporte não está desvinculada da necessidade de se aprender a competir. Seja nas aulas de Educação Física escolar (ensino formal) ou nas Escolas de Esportes ou Centros de Treinamento (ensino não-formal) (SCAGLIA; MONTAGNER; SOUZA, 2001; SCAGLIA; GOMES, 2005).

"Goste-se ou não, a competição e a concorrência são a alma e o grande motor do desporto e da vida", segundo Bento (2006, p. 14). Deste modo, não podemos negá-la e nem dar a ela um valor inferior. Porém, não se trata de qualquer competição. ${ }^{1} \mathrm{E}$ se estamos falando de uma competição escolar, a qual pressupõe seu compromisso com a educabilidade do sujeito, entendemos que esta deve estar consciente de suas particularidades e função. Logo, seus princípios e condutas pedagógicas terão de responder os motivos (por que), para quem, o quê, quando e como a competição será apresentada - ensinada, conforme Scaglia e Souza (2004) e Santana e Reis (2006).

A competição não se encerra apenas nas fronteiras das práticas esportivas corporais, mas assume e transcende à plenitude da própria condição humana e de humanização ao reconhecer os competidores competindo.

Por fim, acreditando que "a competição em si não é boa ou má, ela é o que fazemos dela”, segundo Ferraz (2002, p. 37), propomos, neste trabalho, uma reflexão das competições no interior da escola, sustentadas na ação, e apresentamos uma proposta pedagógica em que acreditamos e defendemos, enquanto referencial para as competições pedagógicas.

1 Não estamos falando de uma competição impregnada pela ideologia capitalista, a qual reforça a idéia da vitória a qualquer preço, nem mesmo de uma proposição alienada de que precisamos formar competidores para sobreviverem na sociedade capitalista.

\section{A reflexão na ação: os jogos interclasses}

Os jogos interclasses é um evento organizado e promovido no âmbito escolar entre as turmas e séries. Cada escola detém particularidades na organização do evento, o qual varia de acordo com a disponibilidade de espaço físico, recursos humanos, materiais e calendário. De modo geral, é uma época em que as atividades de sala de aula dão lugar às atividades esportivas.

Um dos principais problemas relacionados à manifestação do esporte escolar são as dúvidas quanto a sua função educacional, principalmente pelo fato de não se perguntar para quem é o esporte, e pela falta de um enfoque educativo claro (SCAGLIA; MONTAGNER; SOUZA, 2001; BARBIERI, 2001; TURPIN, 2002).

Essas dúvidas estão geralmente relacionadas ao modelo de competição esportivizada, reproduzido no interior da escola, e resultaram em sérias críticas ao esporte escolar. Segundo Paes (2001, 2002), esse modelo se caracteriza pela repetição fechada de fundamentos e gestos técnicos de diferentes modalidades, descomprometida com as intenções e os respectivos objetivos do cenário em que está acontecendo. $\mathrm{Na}$ tentativa de reproduzir, no interior da escola, o modelo de esporte de rendimento, no qual se depara com uma série de fatores que não permite seu inteiro desenvolvimento, acaba se sustentando apenas como uma atividade esportivizada, com um fim em si mesmo.

Os problemas desse modelo estão geralmente associados à visão do adulto em detrimento dos anseios do próprio aluno, tendo ele (o aluno) que se adaptar aos padrões estruturais e organizativos de grandes eventos esportivos institucionalizados (DE ROSE Jr., 2002; FERRAZ, 2002; SCAGLIA; GOMES, 2005).

Segundo Ferreira (2000), existe, nesse modelo, uma demasiada ênfase na competição, sendo seu principal fim e mecanismo avaliativo a vitória, acarretando muitas vezes encontros violentos entre turmas e séries, transformando-se em verdadeiras guerras. 
Essa situação antecede até mesmo ao próprio evento, nas aulas de Educação Física regular. As aulas acabam se tornando verdadeiros espaços de treinamento para as equipes representantes de cada turma. Os protagonistas são exclusivamente os melhores e quase sempre reduzidos a um seleto grupo, alimentando estereótipos e acarretando a eliminação de qualquer possibilidade da participação de outros alunos.

Fator que sustenta esses problemas é o tratamento que a disciplina de educação física e os eventos, relacionados aos seus conteúdos, recebem da escola, em que quase sempre ficam fora do Projeto Político-pedagógico. Ou também, quando marcada por elementos antipedagógicos, são apenas tratadas como atividades extracurriculares (PAES, 2001; TURPIN, 2002).

Dificilmente esses eventos se encontram nesse documento, pelo fato de ter na escola um caráter de importância inferior. Via de regra, os dias ou semana dos jogos interclasses servem apenas como interposto para os professores de outras disciplinas saírem da rotina de sala de aula e colocarem seus afazeres em dia. Também é extremamente útil para fazer os alunos virem à escola, motivados pelo ambiente do jogo, para que sejam cumpridos os dias letivos exigidos.

A ausência de princípios e procedimentos pedagógicos claros e específicos às características do grupo escolar e da escola é outro fator que contribui para esse modelo. Quando os princípios pedagógicos são inexistentes, ou pouco claros, dificilmente será possível antever para onde a ação educativa será conduzida. Por conseguinte, os procedimentos pedagógicos dificilmente serão claros.

Ademais, o que nos apresenta é a necessidade urgente de transformação do cenário em que se encontram as competições escolares, especialmente no interior da escola. É preciso uma reflexão sustentada na ação e uma ação sustentada na reflexão, para ser capaz de romper com esse modelo alienante e obsoleto de competição. Portanto, é necessário criar um ambiente facilitador de relações sociais, sustentado por princípios e procedimentos pedagógicos.

Comprometidos com a urgência em romper com esse modelo ideológico e pragmático de competição, nos lançamos ao desafio de apresentar, a seguir, alguns princípios e procedimentos didático-metodológicos, respondendo a alguns conceitos fundamentais para a compreensão do esporte e das competições escolares, comprometidos com seu tratamento educativo.

E partindo do pressuposto de Scaglia, Montagner e Souza (2001), Barbieri (2001), Scaglia e Gomes (2005), para os quais, o problema não está na competição esportiva, mas está nas mãos daqueles que a partir dela estabelecem seus fins, entendemos que, através dos eventos esportivos, é possível promover a restauração do humano, em face da necessidade de construirmos um mundo melhor, a partir das virtudes educativas existentes na competição pedagógica.

\section{A proposta pedagógica que defendemos para as competições escolares}

Ao defender uma proposta pedagógica para as competições escolares, nos posicionamos e apresentamos nossa compreensão em relação a sua manifestação na escola. Para isso, será necessário repensar o sistema de competição atual e prática esportiva, dentro da escola. Todavia, não poderá ser feita de forma periférica, considerando apenas um único foco.

Como verificamos e que nos faz divergir de Bassani, Torri e Fernandez Vaz (2003), em relação às práticas esportivo-corporais na escola. Segundo os autores, a manifestação das práticas esportivo-corporais na escola, principalmente nas aulas de Educação Física, é o principal alimentador dos rituais de disciplinamento corporal. O problema é que Bassani, Torri e Fernandez Vaz (2003) esqueceram-se de perguntar, em sua investigação, se os rituais de disciplinamentos encontrados foram realmente 
culpa do esporte ou se foram dos professores de Educação Física investigados, incapazes de iniciar uma reflexão, alienados e acomodados com o sistema vigente, reproduzindo modelos obsoletos de competições, que reforçam as características altamente competitivas do mundo, do individualismo e da seletividade.

Desse modo, entendemos que mais importante que tentar compreender a competição, é compreender o sujeito que compete, assim como os sujeitos que especificam seus fins (GARCIA, 2002).

Para apresentarmos a proposta que defendemos para as competições pedagógicas na escola, sobressai, inicialmente, a necessidade de elucidar um problema conceitual com relação aos eventos esportivos escolares: os jogos interclasses é um evento da escola ou na escola?

Aparentemente essa é uma questão ultrapassada e suficientemente gasta nas discussões em Pedagogia do Esporte. Contudo, temos motivos suficientes para acreditar que a escola (ensino formal) ainda não conseguiu romper com a reprodução do modelo de competição na escola, pelo fato de ainda mantê-la por meio dos estereótipos das competições institucionalizadas, pela ausência de um tratamento pedagógico comprometido com a educabilidade do sujeito e pela falta de compromisso da escola com as competições no ambiente escolar.

Quando a competição apenas acontece na escola, não existe um comprometimento intrínseco aos seus objetivos e função. Nesse caso, ela apenas reproduz um sistema espetacularizado. O compromisso é exterior aos objetivos e à função da escola, atendendo apenas aos anseios do sistema competitivo institucionalizado e suas transgressões, repelindo de si qualquer responsabilidade pedagógica e valorizando a escravidão pelos resultados.

O modelo de competição que defendemos está conceitualmente impregnado com a responsabilidade da educabilidade do sujeito. Por isso, a defendemos como uma competição da escola, integrada ao Projeto Político-Pedagógico curricular; um projeto maior - global e orientado para o processo, enquanto instrumento para o sujeito (FERREIRA, 2000; TURPIN, 2002; MOTA, 2003).

Portanto, as competições ou eventos esportivos estarão integrados no programa curricular, como produto do Projeto Político-Pedagógico da escola, desenvolvido na área de conhecimento e objeto de estudo da disciplina de Educação Física, de forma interdisciplinar ou transdisciplinar, pautado nos ideários filosóficos educacionais da escola. Um projeto contextualizado e referenciado pelo tema central da escola, permitindo ser abordado por diferentes disciplinas e conteúdos.

O tratamento pedagógico, para uma educação comprometida com a transformação das competições escolares, tem que partir de um novo olhar sobre as formas de organização, intenções educativas e metodologia, assim como seus conteúdos e critérios de avaliação, priorizando o sujeito no processo (TURPIN, 2002; DE ROSE Jr.; KORSAKAS, 2006).

Partindo dos pressupostos pedagógicos existentes na competição, os quais poderão ser explorados, o objetivo da competição pedagógica na escola deverá ser em torno de maximizar os aspectos positivos e minimizar os efeitos negativos. Os valores de humanização, nas relações interpessoais, a busca pelo equilíbrio entre as relações de prática e resultado, o valor sócio-cultural na coexistência, são aspectos importantes a serem acentuados (SCAGLIA; MONTAGNER; SOUZA, 2001).

\section{Pressupostos metodológicos para uma proposta de competição pedagógica para os jogos da escola}

Ao pensar em uma proposta de competição pedagógica, Turpin (2002) nos diz que o elemento fundamental deve ser a colaboração, e que deveremos fazê-la a partir da compreensão de três conceitos: competição, cooperação e valores sociais. Segundo o autor, mais importante que considerar isoladamente cada conceito, o 
fundamental é identificar suas interlocuções. De tal modo, é necessário que o ensino se concretize de forma competitivo-colaborativa, facilitando uma significativa melhora no grau de cooperação entre companheiros e adversários, para que, assim, todos possam apropriar-se dos benefícios da competição.

Pensando nos princípios que poderiam nortear uma competição pedagógica, Barbieri (2001), Scaglia, Medeiros e Sadi (2006) e De Rose Jr. e Korsakas (2006) sugerem alguns princípios, como: totalidade - do sujeito, cuja emoção, pensamentos e ações, distingue sua identidade, individualidade, limites e diversidade; co-educação - a partir de trocas recíprocas de experiências na aprendizagem; cooperação - favorecendo no ambiente das ações que o individual seja suspenso em função do coletivo, sem negar a individualidade; participação - em todo o processo como agentes responsáveis pela ação; autonomia - reconhecida na dependência de forma inseparável, possam exercê-la com liberdade e formar uma reflexão crítica; e, pluralidade cultural - preservando, valorizando e respeitando as diversas manifestações culturais.

Segundo Scaglia, Montagner e Souza (2001), o primeiro princípio pedagógico referencial é ensinar a todos competir. Pressupõe-se, segundo os autores, que a competição deve ser oferecida de forma equilibrada, permitindo aos alunos, constantemente, se depararem com situações complexas e desafiadoras a serem resolvidas. Todos devem ter oportunidades iguais, visto que a competição é um dos conteúdos abordados nos esportes, e vivenciar um tempo suficiente para explorar as possibilidades reveladas no jogo. $\mathrm{Na}$ condição de mediador, o professor deve ensinar mais que competir, facilitando um ambiente em que o aluno possa deparar com situações que irão guiá-lo para uma aprendizagem de comportamentos e atitudes. Nesse sentido, o professor deve ser capaz de ensinar o aluno a gostar de esporte, para que possa praticá-lo por toda a sua vida.
De acordo com Scaglia, Montagner e Souza (2001), Barbieri (2001), Turpin (2002) e Mota (2003), não podemos pensar em competição, principalmente para crianças e jovens, sem que sejam conhecidos seus pressupostos e princípios pedagógicos. É a partir deles que especificaremos aquilo que irá ser valorizado na ação da prática educativa, no delineamento procedimental e didático-metodológico.

Assim começamos por três aspectos fundamentais: a análise dos critérios especificados para a organização do evento, as intenções educativas e a proposta metodológica. O critério referencial para a organização, de acordo com Paes (2006), De Rose Jr. e Korsakas (2006), deve ser a oportunidade de todos apresentarem o quanto evoluíram e a possibilidade de triunfo, priorizando o máximo de jogos. A rigor, o sistema organizacional terá a incumbência de facilitar e priorizar um processo em que as características do grupo sejam respeitadas e referenciais para o competir. Do mesmo modo, esse sistema é responsável pela maximização de fatores positivos ou negativos da competição.

A organização corresponde a todo o processo de periodização, especificação e execução do cronograma de atividades em cada período, recursos humanos, atividades propostas, materiais necessários, espaços, estruturas a serem modificadas e adaptações, assim como participação direta e indireta dos alunos, demais professores, pais e comunidade na organização e execução, critérios para premiação e avaliação do evento.

A organização da competição não pode ter um fim nela mesma, mas um meio para a educação. Por isso, segundo Scaglia, Medeiros e Sadi (2006), a competição não se inicia apenas quando o árbitro apita para começar, ou encerra quando termina o jogo, mas desde a preparação do evento marcando o sentido de congraçamento e responsabilidade entre os alunos, passando por uma série de manifestações de relações sociais e culturais, garantindo a participação ativa e motivante de todos, em seu desenvolvimento. 
O balizador para as intençôes educativas é oferecer a todas as crianças experiências desafiadoras, que possam contribuir para a afirmação de suas competências. Ou seja, o referencial é o próprio aluno, jogando com alguém e consigo mesmo, como marco para sua auto-avaliação. Nesse aspecto, Scaglia, Montagner e Souza (2001), Barbieri (2001) e Turpin (2002) destacam que a competição deve ser equilibrada, para que todos os participantes tenham condições efetivas de triunfar. Outro aspecto a ser destacado é jogar com o colega adversário ao invés de contra. É mais importante "competir com" ou "contra"? Entendemos que reconhecer o outro e valorizar aquilo que ele fez de melhor para ser apresentado é fundamental, principalmente revelado na necessidade de cooperação com o adversário para existir a competição.

A metodologia responde como (ou aos comos) $)^{2}$ se desenvolve o evento, especificando os procedimentos para vivenciar os conteúdos relacionados à competição pedagógica. $\mathrm{O}$ primeiro aspecto a considerarmos é em relação à participação efetiva de outras disciplinas. Infelizmente a escola ainda organiza o conhecimento de forma compartimentada em um sentido linear e transversal. As disciplinas pouco se relacionam, tornando-se estranhas a elas mesmas.

A realização do evento não é apenas de responsabilidade da disciplina Educação Física, mas responsabilidade da escola. Por isso a interdisciplinaridade é essencial. Por meio da interdisciplinaridade, a competição pode ser abordada por diferentes áreas do conhecimento. Assim é capaz de sustentar objetivos comuns e solucionar inúmeras situações problemas a partir de diferentes pontos de vista, trocando informações fundamentadas nas ações (FAZENDA, 2003).

2 Referimos aos comos no sentido de reconhecer que não trazemos verdades estabelecidas ou absolutas, mas uma contribuição para uma abordagem pedagógica às competições no ambiente escolar.
A co-participação valoriza a participação ativa dos alunos em todo o processo do evento, garantindo sua interferência como agente construtor e responsável pela co-gestão, coresponsabilidade e integração, de tal modo, que favoreça seu comprometimento, gerenciando situações de interesses individuais e coletivos. Por exemplo, na organização das tabelas, na especificação dos itens que compõem o regulamento, divulgação, arbitragem, comissão de alunos para tratar de situações pertinentes às competições, contribuindo para a aquisição de valores como cooperação, solidariedade, convivência, entre outros (BARBIERI, 2001; MOTA, 2003; DE ROSE Jr.; KORSAKAS, 2006).

A co-participação deve se estender à comunidade em geral, para que ela também possa conhecer e se inteirar dos princípios que regem esses eventos. Segundo Mota (2003), há um espaço aberto para a comunidade envolvente, comprometida com a troca de experiências educativas e sócio-culturais.

O evento não pode deixar de ser proposto contextualizado ao programa pedagógico da escola, abordando assuntos emergentes em sua comunidade e datas ou períodos de festividades populares. Ou seja, o projeto deve fazer parte de um processo maior de ensino e aprendizagem, no qual o aluno possa abordar o tema proposto de forma crítica e reflexiva.

A organização desses eventos deve levar em consideração as necessidades da comunidade, onde a escola está inserida. Deste modo, teremos um empenho maior e uma participação mais efetiva da comunidade em geral e mesmo das outras disciplinas, como por exemplo, levando os jogos interclasses para além dos muros da escola; trazendo a comunidade para dentro da escola; refletindo sobre o objetivo real dos jogos interclasses, que vai além do jogar por jogar.

A organização do sistema de competição precisa privilegiar o máximo de encontros possíveis. Para isso, existe possibilidade no encontro da diversidade e multiplicidade 
do conjunto de atividades, combinando jogos esportivos tradicionais, jogos modificados e gincanas de jogos da cultura popular e expressivo. Isto é, estabelecer diferentes formatos de jogos, para atender às diversas intenções e motivações, para que todos participem do evento (TURPIN, 2002).

Do mesmo modo, a organização do evento deve apresentar diferentes tipos de tarefas individuais, cooperativas e de oposição. A intenção de se propor vários tipos de tarefas é permitir que o aluno vivencie diferentes situações problemas de caráter aberto, considerando que as características de uma prova individual diferem em muito de uma atividade de cooperação ou oposição. Por exemplo, alguns alunos não suportam, na competição, o fato de suas ações determinarem o resultado do jogo, ou seja, a derrota ou a vitória. Mas nas atividades individuais, tanto na vitória quanto na derrota, não existe sobre o aluno a pressão dos resultados dos demais colegas. Ou seja, a vitória ou a derrota foram apenas conseqüências de sua ação, não havendo responsabilidade sobre a resultante dos demais colegas. Nesse caso, o desafio e a busca pela auto-superação são os mecanismos referenciais de avaliação do aluno.

A mesma preocupação se volta para as estruturas e objetos que intermedeiam os jogos. Turpin (2002) e Scaglia, Medeiros e Sadi (2006) apresentam algumas modificações pedagógicas possíveis sobre variáveis temporais: duração da competição, número de interrupções, duração do jogo; variáveis espaciais: geografia e dimensões do terreno; variáveis móveis: aumento ou diminuição do tamanho dos obstáculos, do peso, manipulação da forma e da cor; variáveis de jogadores: aumento ou diminuição do número de jogadores; variáveis de resultados: pontuação e recompensas.

Assim sendo, preconizamos a organização, as intenções educativas e metodológicas para a participação democrática de todos nas competições, diminuindo a ênfase sobre o produto e acentuando a preocupação de um processo para o sujeito que aprende na e por meio da competição.

\section{Considerações finais}

É na escola que encontramos, se não a maior, uma das maiores manifestações das práticas esportivas. Por isso a escola não pode negá-las. O problema é que a escola ainda não acredita na possibilidade e função educativa do esporte, sobretudo na competição.

Esse fato se confirma quando consideramos o número de obras e autores que aprofundam as discussões sobre as competições escolares. O esporte encontra na escola uma grande representatividade. A competição é um dos conteúdos do esporte, logo a escola não pode negar nem o esporte e nem a competição. Porque ambos emanam e compõem a essenciabilidade complexa de um fenômeno sócio-cultural. Um sem o outro perderiam em essência o que os caracteriza.

Concordamos com Scaglia, Montagner e Souza (2001) que se pretendemos ensinar o esporte em sua plenitude, temos de ser capazes de ensinar nossos alunos a competir. $\mathrm{E}$ somente se aprende competir, competindo. Entretanto, não se trata de qualquer modelo de competição.

Referimo-nos às competições pedagógicas cientes de suas particularidades e função educacional. Logo, esse modelo de competição tem o desafio de romper com a ideologia e o paradigma reducionistas, que sustentam os sistemas atuais, em que prevalece o ideário de ganhar a qualquer custo, o individualismo e a escravidão dos resultados. As reflexões e ações sobre as competições escolares terão de superar os modelos esportivizados, a visão do adulto em detrimento dos anseios da criança e seu caráter secundário e inferior dentro da escola.

Com o propósito de contribuir para o desafio da urgência nas transformações dos modelos de competição, defendemos uma proposta pedagógica para as competições escolares conceitualmente proposta, enquan- 
to evento da escola e integrado ao Projeto Político-Pedagógico, impregnado com a responsabilidade da educabilidade do sujeito.

Como pilares dessa proposta de competição pedagógica, destacamos os conceitos de cooperação, os valores sociais e a competição de forma interconectada. Para então, sustentar os princípios de totalidade, co-educação, cooperação, participação, autonomia e pluralidade cultural, na análise da organização, das intenções educativas e sua proposta metodológica.

A partir desses princípios pedagógicos e conceitos, acreditamos que "aprender pela competição é possível” (DE ROSE Jr.; KORSAKAS, 2006, p. 260). Contudo, mais uma vez salientamos que essa afirmação não se sustenta sem que seja por meio de um tratamento pedagógico, em que as intenções educativas, as condutas e os princípios pedagógicos alimentem a prática educativa.

Portanto, a competição não é boa e nem ruim, ela é aquilo que especificamos para seus fins, tornando-nos responsáveis pelo ambiente pedagógico que satisfaça as necessidades e desejos de crianças e adolescentes. E que, além de fazer diferente, possamos fazer a diferença na escola.

School Sports Competitions: reflection and action in Sport Pedagogy can make a difference

\footnotetext{
Abstract

Competition in school sports is an issue that has always generated heated debate, occasionally disputed among the ones who support it and the ones who reject it. In an attempt to go beyond such arguments, we engaged both in reflecting upon competition as a fundamental element of sports practice, and in presenting a proposal for educational actions that stem from the virtues of competition. The proposal for school sports competition activities that we support is based on the concept of responsible cognitive educability and is systematized through pedagogical and methodological principles. We recommend educational actions that promote democratic participation, with less emphasis on the product and more emphasis on creating a process for subjects who learn through competition.

Keywords: competition at school - school sports - Sport Pedagogy.
}

\section{Competiciones Escolares: reflexión y acción en Pedagogía del Deporte para hacer la diferencia en la escuela}

\section{Resumen}

El tema competición siempre alimentó grandes discusiones, ocasionalmente polarizadas entre los que eran y los que no eran favorables. En la perspectiva de superar esas discusiones, nos propusimos hacer una reflexión de la competición, como elemento fundamental del deporte y presentar una propuesta para la acción educativa a partir de sus virtudes educativas. La propuesta que defendemos para las competiciones escolares, está impregnada con la responsabilidad de la enseñanza del sujeto, sistematizada a partir de los principios pedagógicos y metodológicos. Predicamos una acción educativa con participación democrática de todos, disminuyendo el énfasis a respecto del producto y acentuando la preocupación de un proceso para el sujeto que aprende en la competición y por medio de ella.

Palabras-clave: competición - juegos escolares - Pedagogía del Deporte.

\section{Referências}

BARBIERI, C. A. S. Esporte educacional: uma possibilidade para a restauração do humano no homem. Canoas: Ulbra, 2001.

BASSANI, J. J.;TORRI, D.; FERNANDEZ VAZ,A. Sobre a presença do esporte na escola: paradoxos e ambigüidades. Movimento, Porto Alegre, v. 9, n. 2, p. 89-112, maio-ago. 2003.

BENTO, J. O. Pedagogia do desporte: definições, conceitos e orientações. In: TANI, G.; BENTO, J. O.; PETERSEN, R. D. S. (Orgs.). Pedagogia do Desporto. Rio de Janeiro: Guanabara Koogan, 2006.

DE ROSE Jr., D. A criança, o jovem e a competição esportiva: considerações gerais. In: _. (Org.). Esporte e atividade física na infância e na adolescência: uma abordagem multidisciplinar. Porto Alegre: Artmed, 2002.

; KORSAKAS, P. O processo de competição e o ensino do desporto. In: TANI, G.; BENTO, J. O.; PETERSEN, R. D. (Orgs.). Pedagogia do Desporto. Rio de Janeiro: Guanabara Koogan, 2006. 
FAZENDA, I. C. A. Interdisciplinaridade para além da palavra... In: MENESES, J. G. C.; BATISTA, S. H. S. S. (Orgs.). Revisitando a prática docente: interdisciplinaridade, políticas públicas e formação. São Paulo: Pioneira Thomson Learning, 2003.

FERRAZ, O. L. O esporte, a criança e o adolescente: consensos e divergências. In: DE ROSE Jr., D. (Org.). Esporte e atividade fisica na infância e na adolescência: uma abordagem multidisciplinar. Porto Alegre: Artmed, 2002.

FERREIRA, M. S. A competição na Educação Física Escolar. Motriz, Rio Claro, v. 6, n. 2, p. 97-100, jul.-dez. 2000.

GARCIA, R. P. Contributo para uma compreensão do desporto - uma perspectiva cultural. In: BARBATIN, V. J.; BENTO, J. O.; MARQUES, A. T.; AMADIO, A. C. (Org.) Esporte e atividade fisica: interação entre o rendimento e qualidade de vida. São Paulo: Manole, 2002.

MOTA, R. B. P. Desporto Escolar: organização, dinamização da atividade interna. Horizonte, Lisboa, v. 19, n. 109, dossier, p. 1-8, 2003.

PAES, R. R. Educação Física Escolar: o esporte como conteúdo pedagógico do ensino fundamental. Canoas: Ulbra, 2001.

A Pedagogia do Esporte e os jogos coletivos. In: DE ROSE Jr. (Org.). Esporte $e$ atividade física na infância e na adolescência: uma abordagem multidisciplinar. Porto Alegre: Artmed, 2002.

Pedagogia do Esporte: contextos, evolução e perspectivas. Revista Brasileira de Educação Física e Esporte, São Paulo, v. 20, Suplemento n. 5, p. 171, set. 2006.

REVERDITO, R. S.; SCAGLIA, A. J. Pedagogia do Esporte: uma análise conceitual das principais abordagens. In: CONGRESSO CIENTÍFICO LATINO-AMERICANO
DE EDUCAÇÃO FÍSICA, 4., 2006, Piracicaba. Anais... Piracicaba: Universidade Metodista de Piracicaba, 2006. v. 1, n. 1.

SANTANA, W. C.; REIS, H. H. B. A Pedagogia do Esporte e o Desafio de Educar para a Autonomia. In: MOREIRA, E. C. (Org.). Educação Física Escolar: desafios e propostas 2. Jundiaí, SP: Fontoura, 2006.

SCAGLIA, A. J.; MONTAGNER, P. C.; SOUZA, A. J. Pedagogia da competição em esportes: da teoria à busca de uma proposta prática escolar. Motus Corporis, Rio de Janeiro, v. 8, n. 2, p. 20-30, 2001.

SCAGLIA, A. J.; MEDEIROS, M.; SADI, R. S. Competições Pedagógicas e Festivais Esportivos: questões pertinentes ao treinamento esportivo. Revista Virtual EFArtigos, Natal/RN, v. 3, n. 23, abril, 2006. Disponível em: <http://efartigos.atspace.org/ esportes/artigo68.html>. Acesso em: 10 nov. de 2006.

SCAGLIA, A. J.; SOUZA, A. Pedagogia do Esporte. In: COMISSÃO DE ESPECIALISTAS - ME. Dimensões pedagógicas do esporte. Brasília: Unb/Cad, 2004.

SCAGLIA, A.; GOMES, R. M. O jogo e a competição: investigações preliminares. In: VENÂNCIO, S.; FREIRE, J. B. (Orgs.). $O$ jogo dentro e fora da escola. Campinas, SP: Autores Associados, 2005.

TURPIN, J. A. P. La competición en el ámbito escolar: um programa de intervención social. 2002. 276 f. Tesis (Doctorado Educación) - Facultad de Educación - Departamento de Didáctica General y Didáticas Específicas - Universidade de Alicante, Alicante, 2002.

Recebido: 16 de maio de 2007

Aprovado: 21 de agosto de 2007

Endereço para correspondência riller.reverdito@unasp.edu.br ascaglia@terra.com 